Check for updates

Cite this: RSC Adv., 2017, 7, 34435

\title{
Improvement of physical properties of palm stearin and soybean oil blends by enzymatic interesterification and their application in fast frozen food
}

\begin{abstract}
Tingwei Zhu, $\dagger^{\mathrm{a}}$ Yali Zhao, $\dagger^{\mathrm{a}}$ Minhua Zong, ${ }^{\mathrm{a}}$ Bing Li, ${ }^{\mathrm{ab}}$ Xia Zhang ${ }^{\mathrm{ab}}$ and Hong Wu (D) *ab
In order to obtain good quality special fats for fast frozen food, blends of palm stearin (PS) and soybean oil (SO) $(5: 5,6: 4$ and $7: 3$, PS : SO) were subjected to enzymatic interesterification in a fluidized bed reactor. The slip melting point of the interesterified blends thus obtained was $45^{\circ} \mathrm{C}$ when the flow rates were 2.24 , 1.57 and $0.40 \mathrm{~mL} \mathrm{~min}{ }^{-1}$, respectively. After interesterification, the contents of SSS- and UUU-type TAGs decreased, whereas the contents of SUU-type TAGs increased. In addition, the $\beta$ form crystal reduced and $\beta^{\prime}$ form crystal increased due to the change in the type of TAGs. The solid fat content of the interesterified blends was $5-40 \%$ at $10-45{ }^{\circ} \mathrm{C}$. The results of sensory evaluation indicated that the special fats prepared from the interesterified blends had better quality when they were applied in the preparation of fast frozen dumplings. Hence, enzymatic interesterification is promising in preparing highquality special fat for fast frozen food.
\end{abstract}

Received 8th March 2017

Accepted 25th June 2017

DOI: $10.1039 / c 7 r a 02829 f$

rsc.li/rsc-advances demonstrated that trans-fatty acids would be inevitably generated during the hydrogenation of vegetable oils. ${ }^{5}$ It has been proven that the intake of trans-fatty acids would increase the risk of cardiovascular diseases. ${ }^{6}$ Refined animal fats are rich in saturated fatty acid and have high melting points. In addition, the granular crystal in animal fat-formulated margarines and shortenings, which may be in relation to the $\beta$ polymorph transformation, impairs their consistency and plasticity, resulting in rubbing feel when the fat melt in mouth. ${ }^{7,8}$ The negative effects associated with trans-fatty acids and saturated fats paved the way for the development of special fats having a specific structure with improved quality for fast frozen food.

Interesterification is one of the most important oil and fat modification technologies, which has received increasing attention in the production of trans-free plastic fats by rearranging the distribution of fatty acids on the glycerol backbone without changing their composition. Compared with chemical interesterification, enzymatic interesterification has numerous advantages such as milder reaction condition, fewer byproducts and lesser pollution to the environment. ${ }^{9}$ The properties of the interesterified blends such as slip melting point, plastic range and crystals would alter after enzymatic reaction, and they can provide desirable properties and smoother mouth feel for food products. ${ }^{10,11}$ However, little has been known about the relationship between the physicochemical property of special fats and the quality of fast frozen food prepared using these special fats. Ma et al. found that the fast frozen food had quite a good quality and mouth feel when it was prepared using the special fats with a slip melting point of $45^{\circ} \mathrm{C}$; however, they
${ }^{a}$ School of Food Science and Engineering, South China University of Technology, Guangzhou 510640, China. E-mail: bbhwu@scut.edu.cn; Tel: +86-20-22236669

${ }^{b}$ Guangdong Province Key Laboratory for Green Processing of Natural Products and Product Safety, Guangzhou 510640, China

$\dagger$ This authors have the same contribution and are co-first authors. 
did not further investigate the physicochemical properties and the polymorphs of these special fats., ${ }^{2,12}$

Palm stearin (PS), a palm oil fraction, cannot be used directly for edible purposes due to its high slip melting point. However, it can be appropriately interesterified with vegetable oils in order to modify its physicochemical characteristics. ${ }^{13}$ Soybean oil (SO) is a type of widely used edible liquid oil with advantages of low price, high productivity as well as abundant nutrition. Therefore, in this study, the base oil of the special fats for fast frozen food was produced by lipozyme TL IM-catalyzed interesterification of palm stearin (PS) and soybean oil (SO) with different mass ratios $(5: 5,6: 4$ and $7: 3$, PS : SO) in a fluidized bed reactor. The slip melting point of approximately $45^{\circ} \mathrm{C}$ was considered as the evaluation index for the interesterified blends. In order to reveal the relationship between the microscopic structure and the macroscopic physical properties of the blends before and after interesterification, the triacylglycerol (TAG) distribution, solid fat content profiles, thermal properties, crystal polymorphisms and crystal microstructure were analyzed. In addition, the interesterified blends were used as base oil to prepare the special fats for fast frozen food. In order to evaluate their qualities, the resulting special fats were applied in the preparation of fast frozen dumplings, the sensory properties of which were further investigated. The interesterified blends with improved physical properties are favorable for the preparation of high-quality special fats for fast frozen food industry.

\section{Materials and methods}

\subsection{Materials}

Refined, bleached and deodorized palm stearin (PS, slip melting point $52.0^{\circ} \mathrm{C}$ ) was supplied by Shenzhen Jingyi Co. (Shenzhen, China), and soybean oil (SO) was purchased from a local grocery store. Lipozyme TL IM (1,3-specific immobilized lipase, $250 \mathrm{IUN}^{-1}$ ) was purchased from Novozymes (Guangzhou, China), which was stored at $-4{ }^{\circ} \mathrm{C}$ before use. The commercial fat was obtained from Kerry Oil Chemical Industry (Tianjin) Co., Ltd. All other reagents and solvents were of highperformance liquid chromatography (HPLC) grade.

\subsection{Interesterification in the fluidized bed reactor}

The enzymatic interesterification was carried out in a fluidized bed reactor (column length $35 \mathrm{~cm}$, internal diameter $1.2 \mathrm{~cm}$ ) and $10 \mathrm{~g}$ immobilized lipase lipozyme TL IM was packed in the internal column. A peristaltic pump was used to feed the substrate mixture with different mass ratios $(5: 5,6: 4$, and $7: 3$, PS : SO) and control the flow rate. The reaction temperature was set at $60^{\circ} \mathrm{C}$.

\subsection{Determination of slip melting point (SMP)}

The SMP of the interesterified blend was determined according to the AOCS Official Method No. Ce $3-25 .{ }^{14}$ A capillary tube filled with $1 \mathrm{~cm}$ high column of sample was chilled at $4 \pm 1^{\circ} \mathrm{C}$ for $16 \mathrm{~h}$ before being immersed in a beaker with cold water. The water was stirred and heated slowly. The temperature was recorded when the blend in the tube started to rise due to hydrostatic pressure. The temperature at the moment was taken as the SMP, which was determined in triplicate.

\subsection{Triacylglycerol (TAG) and fatty acid composition analysis}

The sample's fatty acid methyl ester (FAME) was prepared according to the AOCS Official Method Ce 2-66 (ref. 15) and subsequently analyzed on a GC-2010 gas chromatograph (GC) equipped with a flame ionization detector (Shimadzu, Tokyo, Japan) and a DB-Wax capillary column (length $30 \mathrm{~m}$, internal diameter $0.25 \mathrm{~mm}$, film thickness $0.25 \mu \mathrm{m}$, Agilent Inc., USA). The temperatures of the injector and the detector were $260{ }^{\circ} \mathrm{C}$ and $280^{\circ} \mathrm{C}$, respectively, and the injection volume was $1 \mu \mathrm{L}$. The column's temperature was kept at $180{ }^{\circ} \mathrm{C}$ for $2 \mathrm{~min}$ and then increased to $210{ }^{\circ} \mathrm{C}$ at a rate of $5{ }^{\circ} \mathrm{C} \mathrm{min}{ }^{-1}$.

The TAGs of the blend were analyzed by reversed-phase highperformance liquid chromatography (HPLC) equipped with an evaporative light scattering detector (ELSD) and a Symmetry C18 column $(5 \mu \mathrm{m}, 4.6 \times 150 \mathrm{~mm})$. The blend $(30 \mathrm{mg})$ was dissolved in $30 \mathrm{~mL}$ chloroform and then filtered using a $0.45 \mu \mathrm{m}$ membrane filter before determination. The mobile phase was a binary solvent system of acetonitrile (solvent A) and 2propanol/hexane ( $5: 4$, by volume) (solvent B) and the flow rate was $1.0 \mathrm{~mL} \mathrm{~min}{ }^{-1}$. The detector temperature was $70{ }^{\circ} \mathrm{C}$ and the injection volume was $3 \mu \mathrm{L}$. The individual TAG content was calculated as the percentage of the peak area of individual TAGs relative to the total peak area of the total TAGs in the blend. The identification of TAG species eluted by HPLC is carried out mainly according to its equivalent carbon number (ECN) and the fatty acid composition.

\subsection{Solid fat content (SFC) determination}

A low-resolution pulse nuclear magnetic resonance (pNMR) spectrometer (Bruker, Germany) was used to determine the SFC according to the AOCS Official method Cd $16 \mathrm{~b}-93 .{ }^{16}$ The fat was completely melted by heating at $80{ }^{\circ} \mathrm{C}$ for $30 \mathrm{~min}$ and then cooled to $0{ }^{\circ} \mathrm{C}$ for $60 \mathrm{~min}$ in a high-precision dry bath. Finally, the sample was conditioned at each chosen measuring temperature $\left(0,10,20,30,35,40\right.$ and $\left.45^{\circ} \mathrm{C}\right)$ for $30 \mathrm{~min}$.

\subsection{Differential scanning calorimetry (DSC)}

Analysis of the thermal property was carried out using a differential scanning calorimeter (DSC-Q100, TA Corporation, American). Nitrogen as the purge gas was used at a flow rate of $25 \mathrm{~mL} \mathrm{~min}^{-1}$. An empty DSC pan was used as reference. The sample was first heated to $80{ }^{\circ} \mathrm{C}$ at the rate of $10{ }^{\circ} \mathrm{C} \mathrm{min}-1$ to ensure complete melting and held for $10 \mathrm{~min}$ at that temperature to erase crystal memory. Then, it was cooled from $80{ }^{\circ} \mathrm{C}$ (cooling rate $10{ }^{\circ} \mathrm{C} \mathrm{min}^{-1}$ ) to $-20{ }^{\circ} \mathrm{C}$ for the cooling thermograms. The melting profile was recorded from $-20^{\circ} \mathrm{C}$ to $80^{\circ} \mathrm{C}$ at a heating rate of $5{ }^{\circ} \mathrm{C} \min ^{-1}$.

\subsection{X-ray diffraction (XRD) spectroscopy}

The polymorphic form of fat crystal in the blend was determined by XRD, using $\mathrm{Cu} \mathrm{KR}$ radiation with a Ni filter (voltage 40 
$\mathrm{kV}$; current $40 \mathrm{~mA})$. The sample was scanned from $10^{\circ}$ to $30^{\circ}(2 \theta$ scale) at a rate of $2.0^{\circ} \mathrm{min}^{-1}$ at $24^{\circ} \mathrm{C}$.

\subsection{Polarized light microscopy (PLM)}

The morphology of the blend was imaged using PLM (Axioskop40pol, Leica, Germany) with an attached Canon A640 digital camera (Canon, Tokyo, Japan). An appropriate amount of the sample (approximately $50 \mathrm{mg}$ ) was placed on a carrier glass slip pre-cooled to the desired temperature $\left(25^{\circ} \mathrm{C}\right)$. Then, a cover glass slip was placed parallel to the plane of the carrier slide and centered on the drop of sample to ensure uniformity. The photomicrograph of the crystal was recorded at $50 \times$ magnification.

\subsection{Application of interesterified blends in fast frozen food}

The interesterified blends $(5: 5,6: 4$ and $7: 3$, PS : SO) were used as the base oil to prepare special fats for fast frozen food. The specific steps of making special fats are as follows. The oil phase $(84 \%$, wt $\%)$, the water phase $(15 \%$, wt $\%)$ and the emulsifier (Span-60: trimethylene glycol ester: soybean lecithin: $1: 1: 8,1 \%$, wt $\%$ ) were fully mixed at $60^{\circ} \mathrm{C}$ and $2000 \mathrm{rpm}$ for $20 \mathrm{~min}$. The resulting mixtures were kept at $40{ }^{\circ} \mathrm{C}$ for $10 \mathrm{~min}$. After that, they were put into a bath $\left(-10^{\circ} \mathrm{C}\right)$ and mixed at $300 \mathrm{rpm}$ for $2 \mathrm{~min}$, and then kept at $25^{\circ} \mathrm{C}$ for $48 \mathrm{~h}$.

The special fats prepared from the interesterified blends ( $5: 5,6: 4$ and $7: 3$, PS : SO) and the commercial fat were used in the production of fast frozen dumplings. The specific steps of making fast frozen dumplings are as follows. First, the dumpling pellicles were prepared. To obtain soft dough, $450 \mathrm{~g}$ flour, $7 \mathrm{~g}$ salt, $14 \mathrm{~g}$ special fat and $250 \mathrm{~g}$ water were placed into a bowl and kneaded until the dough became smooth and slightly elastic. The dough without fat was used as the control. Then, the dough was rolled into a long roll, which was cut into equal pieces. Following this, each piece was pressed to be a circular pellicle (diameter $60 \mathrm{~mm}$, thickness $2 \mathrm{~mm}$ ). Second, the filling was prepared by mixing $300 \mathrm{~g}$ fatty ground pork, $600 \mathrm{~g}$ chive and $30 \mathrm{~g}$ salt in a bowl and stirring sufficiently. Finally, the dumplings were obtained by placing the same mass weight filling on the central part of the circular pellicle and sealing the edge of the circular pellicle thoroughly to enclose the filling completely. The prepared dumplings were frozen at $-30{ }^{\circ} \mathrm{C}$.

The sensory analysis was performed by 20 non-trained panelists who were recruited from the students and staff members of the department. At the same time, the panelists were seated in individual testing areas and given a brief orientation on the testing method. The important sensory attributes selected as appropriate indexes for evaluating the quality of fast frozen dumplings were cracking rate, appearance, boil-resisting ability and mouth feel. The results were recorded using a 5point scale (1 point indicates very poor (weak), whereas 5 point denotes very well (strong)) for each attribute and the overall acceptability.

All the experiments were carried out in triplicate and the results were presented as the average values with standard deviations.

\section{Results and discussion}

To achieve the interesterified blends with specific SMP, the blends of PS and SO with different mass ratios (5:5, $6: 4$ and $7: 3$, PS : SO) were catalyzed by lipozyme TL IM in a fluidized bed reactor. When the flow rate was $2.24 \mathrm{~mL} \mathrm{~min}^{-1}$, the SMP of the interesterified blend of PS : SO $(5: 5)$ was $45{ }^{\circ} \mathrm{C}$. The flow

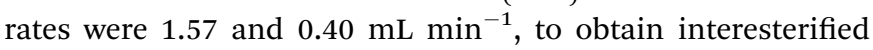
blends of $6: 4$ and $7: 3$ PS : SO, respectively, at $45{ }^{\circ} \mathrm{C}$. The physicochemical properties of the resulting interesterified blends were analyzed, and their application in the preparation of fast frozen food was investigated.

\subsection{TAG profiles and fatty acid composition}

The fatty acid composition and TAG profiles of palm stearin (PS) and soybean oil (SO) blends before and after enzymatic interesterification are given in Tables 1 and 2, respectively. Apparently, enzymatic interesterification did not induce a significant variation in the fatty acid composition, but it changed the TAG profile of different blends. The TAG composition of the blends ( $5: 5,6: 4$ and $7: 3$, PS : SO) before and after interesterification are given in Table 2 . According to the number of unsaturated fatty acids, TAGs were divided into four types, namely SSS, SUS, SUU and UUU (S-saturated fatty acid, U-unsaturated fatty acid). The interesterified blends were mostly composed of TAG species with ECN 44 (LLO and PLL), ECN 46 (LOO, PLO, PPL and PPM), ECN 48 (OOO, SLO, POO, POP/PPO and PPP) and ECN 50 (SOO, POS/PSO and PPS). The content of TAGs with ECN 44 (LLO, PLL) increased with the reduction in PS in the blends. The interesterification caused a decrease in the contents of SSS- and UUU-type TAGs and an increase in the contents of SUU- and SUS-type TAGs. The contents of SSS-type TAGs in the blends ( $5: 5,6: 4$ and $7: 3$, PS : SO) declined from $21.7 \%, 25.1 \%$ and $29.7 \%$ before interesterification to $15.7 \%, 16.3 \%$ and $17.5 \%$ after interesterification, respectively. Similarly, the contents of UUU-type TAGs decreased from $28.4 \%, 22.8 \%$ and $14.5 \%$ to $22.0 \%, 16.2 \%$ and $11.9 \%$, respectively. However, SUU-type TAGs increased from $22.0 \%, 20.6 \%$ and $19.8 \%$ to $36.0 \%, 39.6 \%$ and

Table 1 Fatty acid composition of palm stearin (PS) and soybean oil (SO) blends before and after enzymatic interesterification ${ }^{a}$

\begin{tabular}{|c|c|c|c|c|c|c|}
\hline \multirow[b]{2}{*}{ Fatty acid/\% } & \multicolumn{3}{|c|}{$\begin{array}{l}\text { Before } \\
\text { interesterification }\end{array}$} & \multicolumn{3}{|c|}{ After interesterification } \\
\hline & $5: 5$ & $6: 4$ & $7: 3$ & $5: 5$ & $6: 4$ & $7: 3$ \\
\hline Myristic (14:0) & 0.36 & 0.41 & 0.57 & 0.37 & 0.39 & 0.52 \\
\hline Palmitic (16:0) & 46.31 & 45.79 & 44.93 & 46.28 & 45.32 & 44.37 \\
\hline Stearic $(18: 0)$ & 3.07 & 3.25 & 3.57 & 3.03 & 3.71 & 3.53 \\
\hline Oleic $(18: 1)$ & 26.03 & 26.79 & 25.98 & 26.04 & 27.12 & 26.57 \\
\hline Linoleic $(18: 2)$ & 22.09 & 21.73 & 21.94 & 22.11 & 22.4 & 21.97 \\
\hline Linolenic (18:3) & 2.14 & 2.03 & 3.01 & 2.17 & 1.06 & 3.04 \\
\hline$\sum \mathrm{SFA}$ & 49.74 & 49.45 & 49.07 & 49.68 & 49.42 & 48.42 \\
\hline$\sum$ USFA & 50.26 & 50.55 & 50.93 & 50.32 & 50.58 & 51.58 \\
\hline
\end{tabular}

${ }^{a}$ Notes: $\sum_{\mathrm{UFA}}$, total unsaturated fatty acids; $\sum_{\mathrm{SFA}}$, total saturated fatty acids. 
Table 2 Relative percent (\%) of triacylglycerol (TAG) in the palm stearin (PS) and soybean oil (SO) blends before and after enzymatic interesterification $^{a}$

\begin{tabular}{|c|c|c|c|c|c|c|c|}
\hline \multirow[b]{2}{*}{ ECN } & \multirow[b]{2}{*}{ TAG } & \multicolumn{3}{|c|}{$\begin{array}{l}\text { Before } \\
\text { interesterification }\end{array}$} & \multicolumn{3}{|c|}{$\begin{array}{l}\text { After } \\
\text { interesterification }\end{array}$} \\
\hline & & $5: 5$ & $6: 4$ & $7: 3$ & $5: 5$ & $6: 4$ & $7: 3$ \\
\hline 40 & LLLn & 1.8 & 1.5 & 1.3 & 0.4 & 0.2 & 0.2 \\
\hline 42 & LLL & 9.8 & 7.9 & 4.0 & 6.2 & 4.1 & 2.6 \\
\hline 42 & LLnP & 0.9 & 0.6 & 0.4 & 1.5 & 1.7 & 1.9 \\
\hline 44 & LLO & 9.8 & 7.1 & 4.3 & 7.1 & 4.8 & 3.1 \\
\hline 44 & PLL & 7.6 & 6.5 & 4.8 & 11.9 & 12.6 & 9.2 \\
\hline 46 & LOO & 5.5 & 4.9 & 3.4 & 5.6 & 4.6 & 4.0 \\
\hline 46 & PLO & 3.4 & 3.6 & 3.4 & 12.0 & 12.6 & 14.0 \\
\hline 46 & PPL & 7.1 & 6.7 & 6.5 & 9.6 & 11.0 & 12.2 \\
\hline 46 & PPM & - & - & - & 0.7 & 0.8 & 0.8 \\
\hline 48 & OOO & 1.5 & 1.5 & 1.5 & 2.7 & 2.5 & 2.1 \\
\hline 48 & SLO & - & - & - & 0.9 & 0.8 & 0.8 \\
\hline 48 & $\mathrm{POO}$ & 7.8 & 8.0 & 9.5 & 9.2 & 11.1 & 12.5 \\
\hline 48 & PPP & 19.1 & 22.4 & 26.5 & 13.0 & 13.5 & 14.1 \\
\hline 48 & $\mathrm{POP} / \mathrm{PPO}$ & 19.0 & 22.9 & 26.8 & 14.0 & 15.9 & 15.5 \\
\hline 50 & SOO & 2.3 & 1.9 & 1.8 & 0.2 & 0.5 & 0.8 \\
\hline 50 & POS/PSO & 1.1 & 1.3 & 2.5 & 2.4 & 2.9 & 3.0 \\
\hline \multirow[t]{5}{*}{50} & PPS & 2.6 & 2.8 & 2.9 & 1.9 & 2.0 & 2.6 \\
\hline & UUU & 28.4 & 22.8 & 14.5 & 22.0 & 16.2 & 11.9 \\
\hline & SUU & 22.0 & 20.6 & 19.8 & 36.0 & 39.6 & 39.6 \\
\hline & SSU & 27.1 & 30.9 & 35.7 & 26.1 & 29.8 & 30.7 \\
\hline & SSS & 21.7 & 25.1 & 29.7 & 15.7 & 16.3 & 17.5 \\
\hline
\end{tabular}

${ }^{a}$ Notes: P, palmitic; M, myristic; S, stearic; O, oleic; L, linoleic; Ln, linolenic. Equivalent carbon number $(\mathrm{ECN})=\mathrm{CN}-2 \mathrm{DB}$, where $\mathrm{CN}$ is the carbon number of TAG and DB is the total number of double bonds in TAG; SSS, trisaturated triacylglycerols; SSU, disaturatedmonounsaturated triacylglycerols; SUU, monosaturated-diunsaturated triacylglycerols; UUU, tri-unsaturated triacylglycerols.

$39.6 \%$, respectively. There was a clear reduction in the content of SSS-type TAGs and an increase in the content of SUU-type TAGs in the blends after interesterification, which was consistent with the previous report. ${ }^{\mathbf{1 7}}$ It was found that the crystal transformation has a relationship with the main TAGs composition. The reduction of SSS-type TAGs would be favorable for the generation of small crystals, ${ }^{18,19}$ and the increase in intermediate melting point of TAGs and SUU-type TAGs tends to generate strong $\beta^{\prime}$ polymorphs. ${ }^{\mathbf{2 0 , 2 1}}$ The TAG profiles of interesterified blends indicate that they are more suitable for the preparation of high-quality special fats for fast frozen food than physical blends.

\subsection{Solid fat content (SFC)}

The SFC profiles of the blends (5:5, $6: 4$ and $7: 3$, PS :SO) before and after interesterification are shown in Fig. 1. The interesterified blends had lower SFC values between 10 and $45{ }^{\circ} \mathrm{C}$ than the physical blends. At $45{ }^{\circ} \mathrm{C}$, the SFC of physical blends varied from $10 \%$ to $15 \%$. However, the SFC of all the interesterified blends was reduced to approximately $5 \%$. Generally, the SFC between $10{ }^{\circ} \mathrm{C}$ and $40{ }^{\circ} \mathrm{C}$ gives a measure of fat plasticity and it also influences fat sensory characteristics. It was reported that shortening had a wide plastic range when its
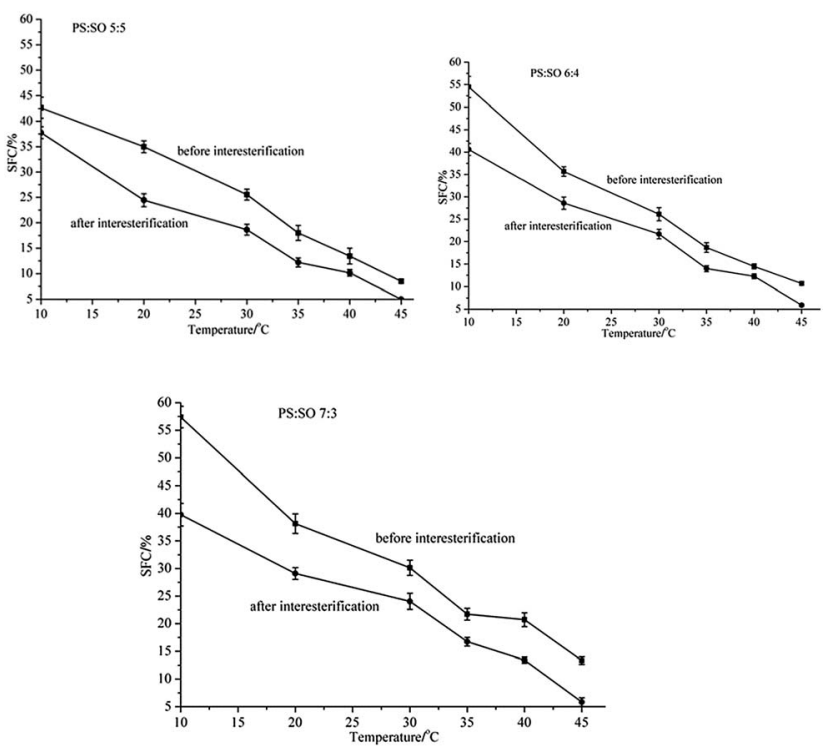

Fig. 1 SFC of the palm stearin (PS) and soybean oil (SO) blends before and after interesterification.

SFCs were $10-45 \%$ between $10{ }^{\circ} \mathrm{C}$ and $40{ }^{\circ} \mathrm{C} .{ }^{22}$ Apparently, the interesterified blends with decreased SFC had a wider plastic range compared with the physical blends. It is well known that the SFC at $10{ }^{\circ} \mathrm{C}$ determines the spread of fat. ${ }^{23}$ The SFCs of physical blends varied from $57.5 \%$ to $42.5 \%$ at $10{ }^{\circ} \mathrm{C}$ with a reduction in the PS : SO ratio, but the corresponding values for the interesterified blends were in the range of $37-41 \%$, indicating that the interesterified blends had better plastic range than the physical blends. The changes in the SFCs of blends are usually related to their TAG profiles. ${ }^{23,24}$ The reduction in the SFC was attributed to the decrease in the content of SSS-type TAGs, and the increase in the content of SUS- and SUUtype TAGs could improve the plastic range of fat and its sensory properties. ${ }^{13,20}$

\subsection{Thermal behavior}

In Fig. 2, melting and crystallization of blends $(5: 5,6: 4,7: 3$, PS : SO) before and after interesterification are presented. The physical blends had higher crystallization onset temperature $\left(T_{\mathrm{co}}\right)$ and melting completion temperature $\left(T_{\mathrm{mc}}\right)$ than the corresponding interesterified blends. As shown in Fig. $2 \mathrm{~A}-\mathrm{C}$, for blends of $5: 5,6: 4$ and $7: 3$ PS : SO, $T_{\mathrm{mc}}$ decreased from 47.6, 48.8 and 49.5 before interesterification to $44.8,45.8$, and 45.2 , respectively, after interesterification. This behavior was highly correlated with the decrease in the content of SSS-type TAGs and the increase in the content of SUS- and SUU-type TAGs after interesterification, which was consistent with the previous report. ${ }^{25}$ It was worth noting that the peak areas of the highest SMP changed to be smaller and close to $45{ }^{\circ} \mathrm{C}$ for all the interesterified blends. The differences in thermal behavior between physical blends and their interesterified blends were attributed to the changes in TAG species. The presence of highmelting TAGs, such as OOO and PPP or SSS species with similar structures in the physical blends, may impart its poor mouth 

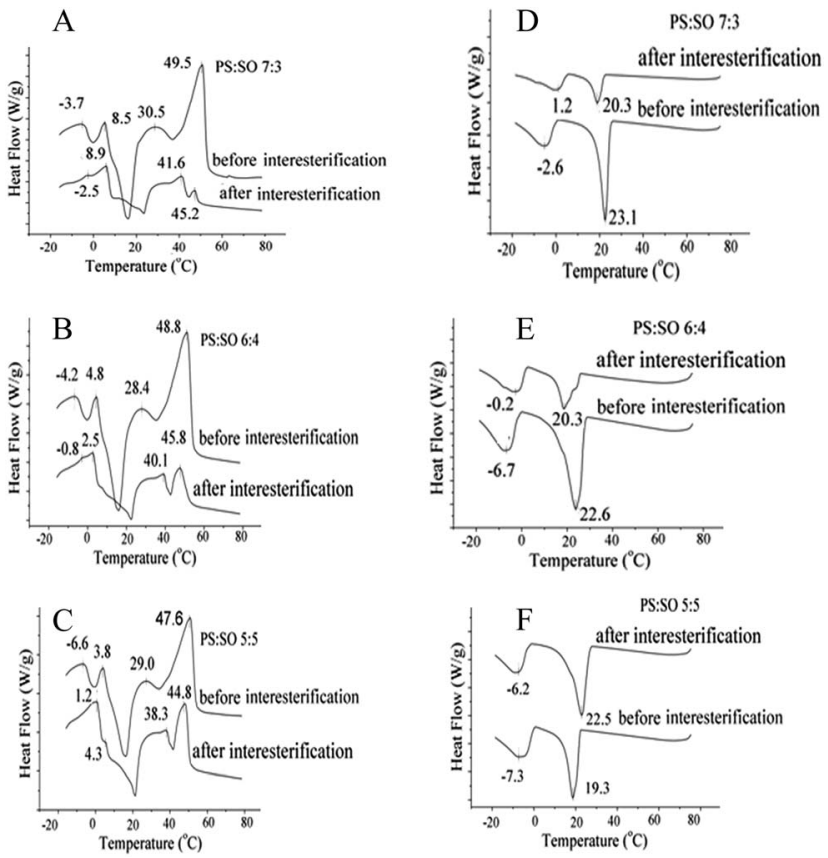

Fig. 2 DSC melting $(A-C)$ and cooling (D-F) curves of the palm stearin (PS) and soybean oil (SO) blends before and after interesterification.

feel. ${ }^{26}$ Fig. 2D-F depicts the crystallization profiles of the blends. After interesterification, the $T_{\text {co }}$ for the blends of $5: 5,6: 4$ and $7: 3$ PS : SO decreased from $1.2,-0.2$ and -6.2 to $-2.6,-6.7$ and -7.3 , respectively. It was reported that the rearrangement of FAs in TAGs after enzymatic interesterification led to the production of new TAG species, which in turn changed the thermal behaviors. ${ }^{27}$

\subsection{Polymorphism}

The crystal polymorphism of the blends $(5: 5,6: 4$ and $7: 3$, PS : SO) before and after interesterification were detected by XRD (Fig. 3). The three representative polymorphic forms of fat crystal are named as $\alpha, \beta^{\prime}$, and $\beta$, and the polymorph could be determined by the short spacing of the crystal. The short spacing of $\alpha$ form (hexagonal) is the least stable and it appears near $4.15 \AA^{11}$ The $\beta$ form (triclinic) is the most stable and has a strong short spacing at $4.6 \AA^{19}$ The $\beta^{\prime}$ form (orthorhombic) displayed a metastable form and has two strong short spacings at about 3.8 and $4.2 \AA^{28}$ The $\beta^{\prime}$ form with small crystals is desirable for providing good texture and properties in most margarines and shortenings. ${ }^{29}$ Before interesterification, the physical blends (5 : 5, $6: 4$ and $7: 3$, PS : SO) showed four short spacings at 4.62, 4.2, 4.31 and $3.83 \AA$, respectively, indicating the coexistence of $\beta^{\prime}$ and $\beta$ form. After interesterification, the intensity of the peak at $4.6 \AA$ significantly decreased, particularly the blend of $6: 4$ PS : SO had the weakest peak intensity at $4.6 \AA$, which indicated that $\beta$ form reduced and $\beta^{\prime}$ form increased. Therefore, in the interesterified blends, their polymorphism showed predominant $\beta^{\prime}$ form crystal. The transformation of polymorphism is dependent on the degree of homogeneity of TAGs. ${ }^{21}$ The PPP mainly tends to form $\beta$ crystal

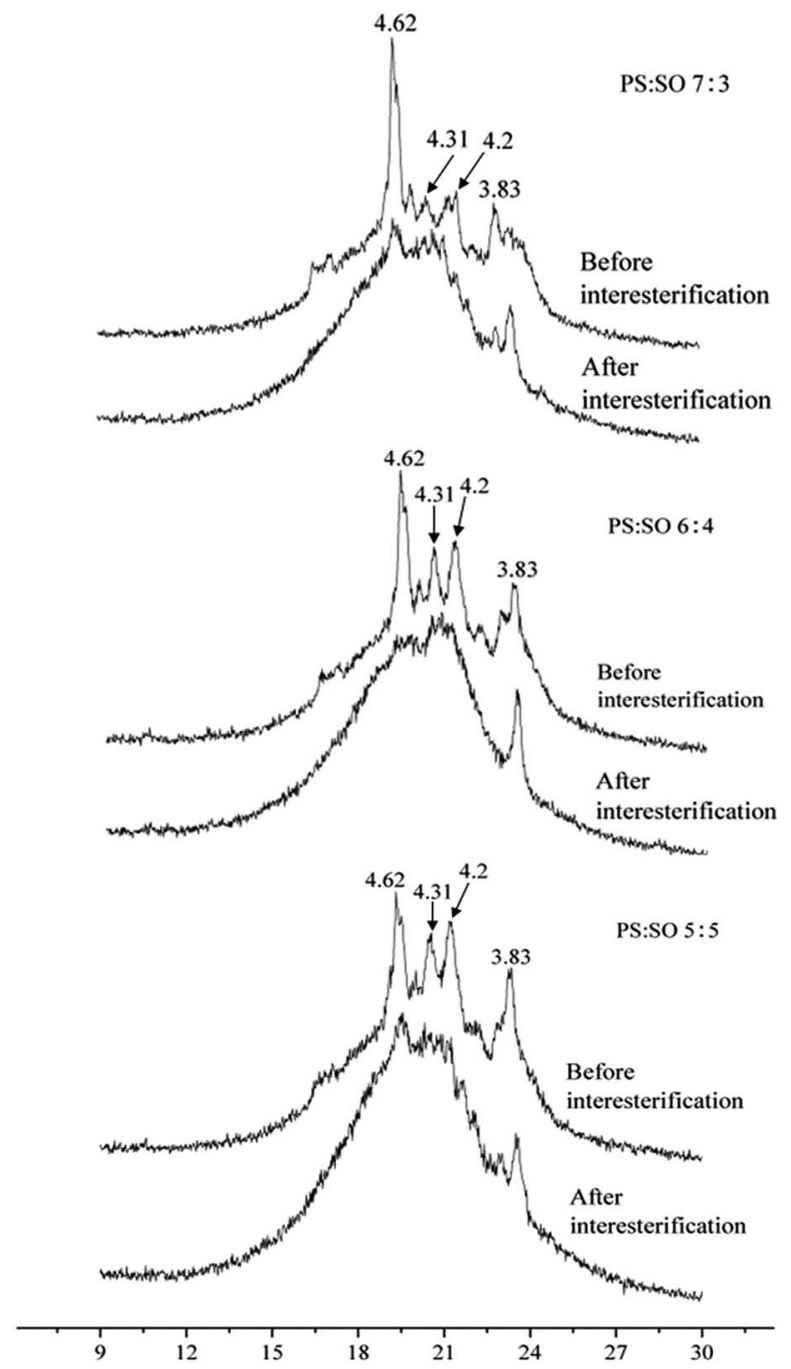

Fig. 3 XRD spectra of the palm stearin (PS) and soybean oil (SO) blends before and after interesterification.

and PLO, POO, and PPS tend to be $\beta^{\prime}$ crystal. ${ }^{17}$ The results given in Table 1 showed that after interesterification, the content of POP and PPP decreased, whereas the content of PLO and POO increased for all the blends. Thus, the interesterified blends canform $\beta^{\prime}$ crystal more easily than the physical blends.

\subsection{Microstructure}

The microstructure of the blends ( $5: 5,6: 4$ and $7: 3$, PS :SO) before and after interesterification were analyzed by polarized light microscopy (PLM) and the result is illustrated in Fig. 4. The crystal morphologies of the blends were explicitly different. The interesterified blends ( $5: 5,6: 4$ and $7: 3$, PS : SO) consisted of crystal aggregates with tightly packed, uniform, needle-shaped crystals, particularly the interesterified blend of $7: 3$ PS : SO. The physical blends exhibited coarse, large symmetrical spherulite-shaped crystals with diameters exceeding $50 \mu \mathrm{m}$. In addition, the crystals tended to aggregate to form clusters with the increase in PS content. The crystal with small size and needle-like structure was $\beta^{\prime}$ crystal and the crystal that 


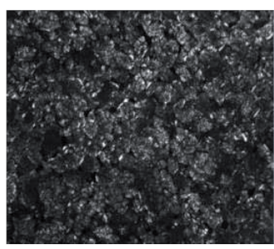

(A) PS:SO 5:5

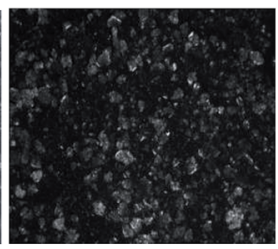

(C) PS:SO 6:4 Before interesterification

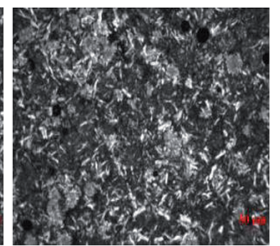

(D) PS:SO 6:4

(B) PS:SO 5

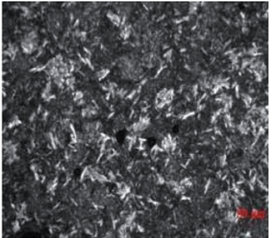

After interesterification

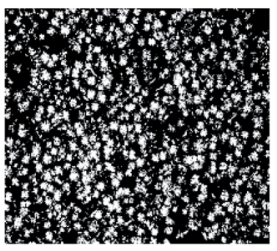

(E) PS:SO 7:3

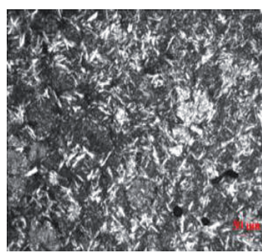

(F) PS:SO 7:3
Fig. 4 PLM image of the palm stearin (PS) and soybean oil (SO) blends before $(A, C, E)$ and after $(B, D, F)$ interesterification.

aggregated to form spherulites with large size corresponded to $\beta$ crystal. ${ }^{21}$ Ribeiro et al. found that the microstructure alteration of the blend of canola oil and fully hydrogenated cottonseed oil after interesterification was attributed to the decrease in symmetrical high-melting-point TAGs (SSS). ${ }^{19}$ Hence, the resulting interesterified blends with the ideal crystal form are much suitable for the preparation of high-quality special fats for fast frozen food.

\subsection{Application of interesterified blends}

In order to evaluate the efficacy of the interesterified blends ( $5: 5,6: 4$ and $7: 3$, PS :SO) in improving the quality of special fat for fast frozen food, they were used as base oil to prepare special fats, which were further applied in the production of fast frozen dumplings. The fast frozen dumpling prepared using commercial fat was used as a comparison and that without fat

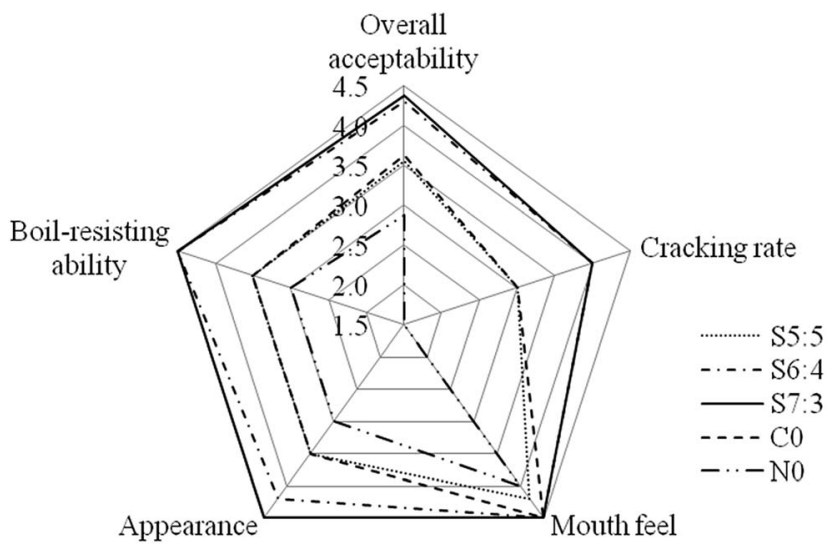

Fig. 5 Sensory evaluation of the fast frozen dumplings (S5: 5, S6: 4, S7: 3 , fast frozen dumplings prepared using special fats with interesterified fats $5: 5,6: 4$ and $7: 3$ PS : SO as base oil, respectively; $C 0$, fast frozen dumplings prepared using commercial fat; N0, fast frozen dumplings prepared without fat). was used as the control. The sensorial properties of these five groups of fast frozen dumplings were investigated by detecting their cracking rate, appearance, boil-resisting ability and mouth feel. As shown in Fig. 5, the fast frozen dumplings prepared using the interesterified blends exhibited low cracking rates, and the cracking rates of these five groups of fast frozen dumplings followed the order: PS : SO $7: 3 \approx$ PS : SO 6:4< PS : SO $5: 5 \approx$ commercial fat $<$ control. The fast frozen dumplings prepared using the interesterified blends $6: 4$ and $7: 3$ had smoother appearance before and after cooking and better boil-resisting ability than other groups, and the orders were PS : SO $7: 3 \approx$ PS : SO $6: 4>$ PS : SO $5: 5 \approx$ commercial fat $>$ control, indicating that addition of fats into fast frozen dumplings decreased their stickiness and improved their tolerance to overcooking. The mouth feel of the fast frozen dumplings prepared using the interesterified fats and the commercial fat were similar and better than that of the control, which was due to the change in the texture of fast frozen dumplings after the addition of fat. The overall acceptability of these five groups of fast frozen dumplings followed the order PS : SO $7: 3>$ PS : SO $6: 4>$ PS : SO $5: 5 \approx$ commercial fat > control, indicating that the special fats prepared from the interesterified blends had better quality in preparation of fast frozen dumplings, particularly for the blends of PS : SO $6: 4$ and $7: 3$. These sensory evaluation results were consistent with the results of previous studies, ${ }^{12,30}$ in which special oils based on interesterified blend were used for preparing dumpling balls. During the freezing process of fast frozen flour product, the movement of water molecules separating from the surface of dough caused the dissipation of the dough. The plastic fat may limit the movement of water and thereby improve the ability of dough to maintain its structure during freezing and storage. ${ }^{31}$ Furthermore, lipids are believed to contribute a desirable mouth feel and influence flavor perception. ${ }^{32}$

Furthermore, the crystal in the plastic fats could impact their application in food products. The $\beta^{\prime}$ form with very small crystals, which enable it to incorporate relatively large amounts of liquid oil in the crystal network, leads to the production of smooth, continuous and homogeneous plastic fats in the application. ${ }^{33}$ Therefore, according to this study, the enzymatic interesterified blend-based special fat with more $\beta^{\prime}$ form crystal has better quality than physical blend-based special fat and commercial fat (data not shown). These results suggest that enzymatic interesterification is an efficient strategy to prepare high-quality special fat for fast frozen food.

\section{Conclusions}

The physical properties of the blends of palm stearin (PS) and soybean oil (SO) (5:5, $6: 4$ and $7: 3$, PS : SO) were improved by enzymatic interesterification. The interesterified blends with specific SMP can be obtained by regulating the flow rate of reactants in the fluidized bed reactor. The SSS- and UUU-type TAGs decreased and the SUU-type TAGs increased after interesterification. The interesterified blends had better plastic range than the physical blends and the SFCs of the interesterified blends were $5-40 \%$ between 10 and $45{ }^{\circ} \mathrm{C}$. The 
interesterified blends were easier to form $\beta^{\prime}$ crystal than the physical blends due to the change in the type of TAGs. The fast frozen dumplings prepared using special fats, which were produced with interesterified blends as base oil, had better sensory characteristics, indicating that enzymatic interesterification is promising in the preparation of high-quality special fat for fast frozen food.

\section{Acknowledgements}

We acknowledge the National Natural Science Foundation of China (NSFC)-Guangdong Joint Foundation Key Project (No. U1501214), the Natural Science Foundation of Guangdong Province (No. 2015A030313217), the National Natural Science Foundation of China (No. 31671852) and the Science and Technology Project of Guangdong Province (No. 2013B010404005) for financial supports.

\section{References}

1 L. L. Li and S. T. Guo, Sci. Technol. Food Ind., 2010, 31, 422424.

2 C. G. Ma, D. F. Li, X. M. Cha and M. Wang, China Oils Fats, 2006, 31, 14-16.

3 L. G. Carr and C. C. Tadini, LWT-Food Sci. Technol., 2003, 36, 609-614.

4 C. G. Ma, D. Z. Wang, L. P. Pan, G. L. Wang, W. M. Wu and R. H. Ge, China Oils Fats, 2009, 34, 10-13.

5 M. B. Fernández, G. M. Tonetto, G. H. Crapiste and D. E. Damiani, J. Food Eng., 2007, 82, 199-208.

6 R. N. Deroos, E. Schouten and M. Katan, J. Nutr., 2001, 131, 242-245.

7 Z. Meng, Y. F. Liu, Q. Z. Jin, J. H. Huang, Z. H. Song, F. Y. Wang and X. G. Wang, J. Agric. Food Chem., 2010, 58, 11463-11470.

8 Z. Meng, Y. F. Liu, Q. Z. Jin, J. H. Huang, Z. H. Song, F. Y. Wang and X. G. Wang, J. Agric. Food Chem., 2011, 59, 1432-1441.

9 R. Costales-Rodríguez, V. Gibon, R. Verhé and W. D. Greyt, J. Am. Oil Chem. Soc., 2009, 86, 681-697.

10 A. Bell, M. H. Gordon, W. Jirasubkunakorn and K. W. Smith, Food Chem., 2007, 101, 799-805.

11 B. H. Jennings and C. C. Akoh, J. Am. Oil Chem. Soc., 2010, 87, 411-417.
12 D. Z. Wang, C. G. Ma, G. L. Wang, W. M. Wu, R. H. Ge and C. L. Liu, J. Chin. Cereals Oils Assoc., 2010, 25, 71-74.

13 S. H. Fauzi, N. A. Rashid and Z. Omar, Food Chem., 2013, 137, 8-17.

14 AOCS, Am Oil Chem' Soci., 2009, Cc 3-25.

15 AOCS, Am Oil Chem' Soci., 2004, Ce 2-66.

16 AOCS, Am Oil Chem' Soci., 2004, Cd 16b-93.

17 S. Jungah, C. C. Akoh and L. Kiteak, J. Agric. Food Chem., 2009, 57, 888-900.

18 B. S. Chu, H. M. Ghazali, O. M. Lai, M. Y. Che and S. Yusof, Food Chem., 2002, 76, 155-164.

19 A. P. B. Ribeiro, R. C. Basso, R. Grimaldi, L. A. Gioielli, A. O. Santos, L. P. Cardoso and L. A. G. Gonçalves, Food Res. Int., 2009, 42, 1153-1162.

20 M. H. Masuchi, K. M. Gandra, A. L. Marangoni, C. D. S. Perenha, M. C. Chiu, R. Grimaldi and L. A. G. Gonçalves, J. Am. Oil Chem. Soc., 2014, 91, 859-866. 21 X. Zhang, L. Li, H. Xie, Z. L. Liang, J. Y. Su, G. Q. Liu and B. Li, Food Bioprocess Technol., 2014, 7, 887-900.

22 S. Q. Zhao, J. N. Hu, X. M. Zhu, C. Q. Bai, H. L. Peng, H. Xiong, J. W. Hu and Q. Zhao, J. Agric. Food Chem., 2014, 62, 3293-3300.

23 I. L. Gold, M. E. Ukhun and C. C. Akoh, J. Am. Oil Chem. Soc., 2011, 88, 1659-1667.

24 S. Danthine, N. D. Clercq, K. Dewettinck and V. Gibon, J. Therm. Anal. Calorim., 2014, 115, 2219-2229.

25 C. A. Álvarez and C. C. Akoh, J. Am. Oil Chem. Soc., 2015, 92, 1003-1014.

26 E. A. Ifeduba, S. Martini and C. C. Akoh, J. Am. Oil Chem. Soc., 2016, 93, 61-67.

27 P. Ornla-led, S. Sonwai and S. Lertthirasuntorn, Food Sci. Biotechnol., 2016, 25, 673-680.

28 P. Adhikari, J. A. Shin, J. H. Lee, J. N. Hu, K. T. Hwang and K. T. Lee, J. Food Sci., 2009, 74, E87-E96.

29 A. Idris, N. M. Zain and M. Y. Noordin, Desalination., 2007, 207, 324-339.

30 X. X. Cui, Y. Wang, Y. L. Zhao, M. H. Zong, B. Li and H. Wu, Mod. Food Sci. Technol., 2014, 30, 187-193.

31 Y. Inoue, H. D. Sapirstein and W. Bushuk, Cereal Chem., 1995, 72, 221-226.

32 A. Goldstein and K. Seetharaman, Food Res. Int., 2011, 44, 1476-1481.

33 I. N. Aini and M. S. Miskandar, Eur. J. Lipid Sci. Technol., 2007, 109, 422-432. 